\title{
Межкраевой плазмон Берри как основа регулируемых однонаправленных устройств без магнитного поля
}

\author{
А.С. Петров \\ Московский физико-технический институт, Долгопрудный, 141701, Институтский пер., 9 \\ эл.nочта: aleksandr.petrov@phystech.edu
}

DOI $10.34077 /$ RCSP2021-82

Мы предсказываем существование нового плазменного возбуждения, которое проявляет хиральные свойства в отсутствие внешнего магнитного поля. Это возбуждение, которое мы называем межкраевым плазмоном Берри (МКПБ), локализовано на границе раздела между двумя двумерными электронными системами (ДЭС) с различными аномальными холловскими проводимостями (рис. 1). Важно отметить,

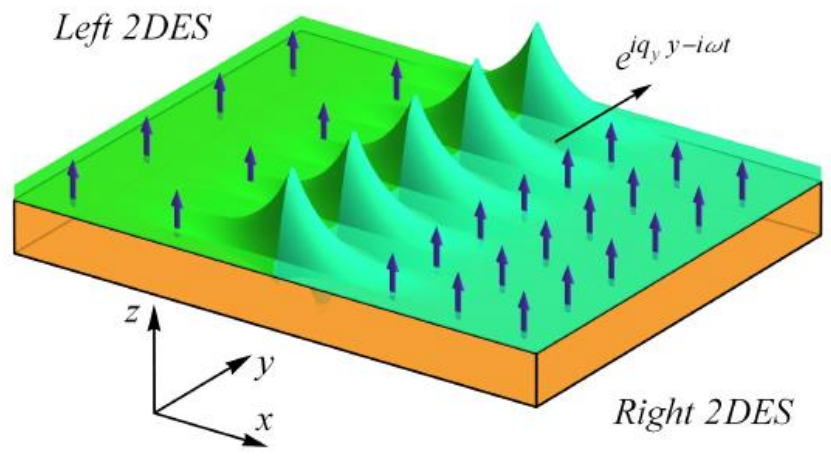

Рис. 1. Схема МКПБ, локализованного на границе двух ДЭС с различными потоками Берри. Зелёная и бирюзовая области обозначают ДЭС, оранжевая область - подложка, плотность стрелочек обозначает поток Берри. Поток Берри - вектор, который упрощённо можно считать встроенным магнитным полем, приводящем к контрасту недиагональных проводимостей. Наличие такого контраста ожидаемо приводит к появлению краевой моды. что МКПБ - это однонаправленная мода, направление распространения и частота которой поддаются контролю извне, в отличие от прочих современных устройств без магнитного поля. Мы считаем, что МКПБ представляет собой уникальную платформу для регулируемой передачи сигнала с защитой от обратного рассеяния в отсутствие магнитного поля.

Дисперсионное соотношение для МКПБ может быть получено путем модификации известной теории межкраевого магнитоплазмона [1]. Согласно этой работе, в локальной модели электронного транспорта с пространственно однородной проводимостью на границе между ДЭС локализована краевая мода (причем не обязательно магнитоплазменная). Принципиальным для образования новой моды является контраст недиагональных проводимостей, который в работе [1] возникал вследствие приложения магнитного поля к контакту ДЭС с разными плотностями носителей.

Мы расширяем эту теорию на случай недиагональных проводимостей, вызванных ненулевым потоком Берри в ДЭС. Ненулевой поток Берри возникает в некоторых материалах с нетривиальной топологией зонной структуры; например, $\mathrm{Bi}_{2} \mathrm{Te}_{3}$, допированным хромом. Недавно было предсказано существование хиральных плазмонов на краю таких материалов [2], а также проведён эксперимент по их наблюдению [3]. Наша работа является продолжением этих исследований.

Нами получено и решено дисперсионное уравнение для МКПБ и показано, что МКПБ является чисто однонаправленной модой, в отличие от [2,3], где обратная мода принципиально присутствовала, но затухала при определенных условиях. Мы показываем, что частота и направление МКПБ могут регулироваться извне (например, напряжением на затворе), что выгодно отличает однонаправленные приборы на основе МКПБ от их конкурентов на базе фотонных топологических изоляторов [4].

Автор выражает благодарность Д. Свинцову за обсуждения и поддержку. Работа поддержана грантом фонда развития теоретической физики и математики "БАЗИС" 18-1-5-66-1 и грантом РФФИ 18-29-20116.

\section{Лumepamypa}

[1] Volkov V. A., Mikhailov S. A. // Sov. Phys. JETP. - 1988. - T. 67. - №. 8. - C. 1639-1653.

[2] Song J. C. W., Rudner M. S. //Proceedings of the National Academy of Sciences. - 2016. - T. 113. - №. 17. - C. 4658-4663.

[3] Mahoney A. C. et al. //Nature communications. - 2017. - T. 8. - №. 1. - C. 1-7.

[4] Yang Y. et al. //Nature Photonics. - 2020. - T. 14. - №. 7. - C. 446-451. 